\title{
Entropy production of soil hydrological processes and its maximisation
}

\author{
P. Porada, A. Kleidon, and S. J. Schymanski \\ Max Planck Institute for Biogeochemistry, P.O. Box 1001 64, 07701 Jena, Germany \\ Received: 17 December 2010 - Published in Earth Syst. Dynam. Discuss.: 28 January 2011 \\ Revised: 13 July 2011 - Accepted: 14 August 2011 - Published: 2 September 2011
}

\begin{abstract}
Hydrological processes are irreversible and produce entropy. Hence, the framework of non-equilibrium thermodynamics is used here to describe them mathematically. This means flows of water are written as functions of gradients in the gravitational and chemical potential of water between two parts of the hydrological system. Such a framework facilitates a consistent thermodynamic representation of the hydrological processes in the model. Furthermore, it allows for the calculation of the entropy production associated with a flow of water, which is proportional to the product of gradient and flow. Thus, an entropy budget of the hydrological cycle at the land surface is quantified, illustrating the contribution of different processes to the overall entropy production. Moreover, the proposed Principle of Maximum Entropy Production (MEP) can be applied to the model. This means, unknown parameters can be determined by setting them to values which lead to a maximisation of the entropy production in the model. The model used in this study is parametrised according to MEP and evaluated by means of several observational datasets describing terrestrial fluxes of water and carbon. The model reproduces the data with good accuracy which is a promising result with regard to the application of MEP to hydrological processes at the land surface.
\end{abstract}

\section{Introduction}

The analysis and modelling of soil hydrological processes on a global scale is a challenging task, mostly due to interactions of the mechanisms involved combined with spatial heterogeneity at many scales. Although single processes (e.g. infiltration or bare soil evaporation) are well understood, a unifying quantitative framework to describe hydrological

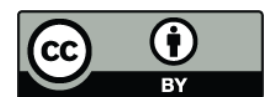

Correspondence to: P. Porada (pporad@bgc-jena.mpg.de) behaviour at catchment or larger scales is still missing (Sivapalan, 2005). It is therefore in general not possible to make correct predictions about a certain catchment or region based on a model that has been designed for another catchment. This paper presents an alternative approach to model hydrological processes. Instead of describing each single process by a standard empirical theory, the framework of nonequilibrium thermodynamics is used. Thermodynamic methods have already been used by Edlefsen and Anderson (1943) to characterise soil moisture relations and they are the theoretical basis of common hydrological state variables, such as the matric potential of soil water. Gradients in matric potential between two locations can then be used to quantify the tendency of the water to move from high to low potentials, e.g. from wet to dry soil. Later, Leopold and Langbein (1962) introduced the concept of entropy production into soil hydrology, using the analogy of a thermodynamic heat engine. Similar to heat moving along a temperature gradient towards the cooler temperature, the authors formulated runoff as a function of the gradient in the gravitational potential of water, which results from topography. By flowing downhill, the water moves from high to low gravitational potential, thereby converting potential energy of water into kinetic energy which is then dissipated into heat by friction. The entropy production of runoff is then proportional to the product of the flow of water and the gradient in gravitational potential. It corresponds to the amount of heat generated by the flow divided by temperature.

Given the basic concepts of water potential and entropy production associated with a flow of water, what is necessary to use thermodynamics as a unifying framework for the description of hydrological processes? The soil is a nonequilibrium open system where gradients in water potential drive flows of water. Assuming local thermodynamic equilibrium (Kondepudi and Prigogine, 1998), a chemical potential of water can be calculated as a function of the water content in a sufficiently small part of the soil hydrological

Published by Copernicus Publications on behalf of the European Geosciences Union. 
system. All exchange flows of water can then be formulated as functions of gradients in the combined chemical and gravitational potential of water. In the following, these combined potentials will be denoted by the term "water potential" and they will be expressed by the symbol for chemical potential ( $\mu$, e.g. Eq. 1). The implementation of the thermodynamic framework described above into a simple land surfacevegetation model is one main motivation for this paper.

Having formulated flows of water as functions of gradients in water potential, it is straightforward to quantify an entropy budget of the most important soil hydrological processes. This can be used to illustrate the relative contributions of different processes to the overall dissipation at the land surface.

Another advantage of a thermodynamic formulation of hydrological processes is the possibility to apply the principle of Maximum Entropy Production (MEP) to the respective models (Kleidon and Schymanski, 2008). This is explained using the example of root water uptake at the global scale. The flow of water from soil to roots is formulated as a linear function of the gradient between soil and root water potential, with a proportionality constant $c$. The value of $c$ comprises all factors affecting the speed of water movement at the root-soil interface such as soil type, macropore density, root density, hydraulic conductivity, etc. which are highly variable at the global scale. In theory, the value of $c$ at a certain place at a certain time is then determined by all these measurable soil and vegetation properties. However, the relation between these properties and $c$ is so unpredictable at the spatio-temporal scale of our model, that $c$ is characterised by a very large range of values. This is also the reason to assume a linear relation between the flow and the gradient in water potential, since it is the simplest model possible, given that not much is known about how $c$ is related to soil and vegetation properties at the scale of this model. At steady state, a maximum in the entropy production associated with root water uptake then results from a trade-off between the flow and the gradient which is driving it: in the presence of alternative pathways (e.g. runoff or bare soil evaporation), high values of $c$ lead to a strong dissipation of the gradient and consequently to a large flow at a small gradient (Schymanski et al., 2009). Conversely, small values of $c$ lead to a large gradient but a small flow. Since the entropy production is proportional to the product of gradient and flow, it shows a maximum at intermediate values of $c$. MEP predicts that the value of $c$ which leads to maximum entropy production is the most probable one, given the model structure and forcing. For reviews about MEP see Martyushev and Seleznev (2006); Ozawa et al. (2003).

MEP and other approaches dealing with the dissipation of free energy have been recently used in hydrology and ecology to predict various properties of land surface systems, ranging from the spatial distribution of biomass in semiarid regions (Schymanski et al., 2010) to preferential flow on hillslopes (Zehe et al., 2010). The aim of the present paper is to determine parameter values of a global land surface model (JESSY/SIMBA, Porada et al., 2010) by MEP. In a second step, the model output based on these parameter values is compared with empirical data to test whether the MEP-based prediction leads to realistic results.

This paper is structured as follows: Sect. 2 contains a description of the most important parts of the model used in this study, followed by the model setup in Sect. 3. In Sect. 4, the results of this study are presented, including a parametrisation of the model according to MEP, an entropy budget of the hydrological cycle at the land surface and an evaluation of the model performance. The paper closes with a discussion and an outlook.

\section{Model description}

The model used in this study simulates terrestrial biogeochemical processes in a simple way at the global scale. It consists of a soil model called JESSY (JEna Surface SYstem model) and a vegetation model, SIMBA (SIMulator of Biospheric Aspects). JESSY and SIMBA use global gridded climate data as input to predict fluxes of carbon and water at the land surface, including evapotranspiration, runoff and Net Primary Productivity (NPP). Furthermore, reservoirs such as soil water, biomass and soil carbon can be quantified. The models use a global rectangular grid with a resolution of 2.8125 degrees (this corresponds to the T42 resolution).

JESSY and SIMBA are designed to run independently, which means that each of the models can be coupled to other models and they do not have to be run together. JESSY, for instance, needs the value of the vegetation water potential to compute root water uptake. This value can be provided by any vegetation model or it could be prescribed as a boundary condition. This increases the applicability of the two models to biogeochemical questions.

Since the models are described in detail in Porada et al. (2010), only the model parts which have been extended or added for quantifying the entropy production of soil hydrological processes are explained here. In JESSY, the entropy production of surface runoff, infiltration, bare soil evaporation, root water uptake and baseflow is quantified for each grid cell of the model using the local potentials of water. Soil water storage is represented by a bucket approach. Transpiration by the vegetation and the associated entropy production is calculated in SIMBA, also for each grid cell. Figure 1 gives an overview of the entropy producing processes considered in the model.

Several processes were not included in the model for reason of simplicity: the entropy production of precipitation takes place mostly in the free atmosphere and is therefore not quantified here. Precipitation that arrives at the surface is then assumed to be in equilibrium with surface water. Water can enter the soil in form of rainwater or snow melt. Processes such as dew or frost are neglected. Water exchange 


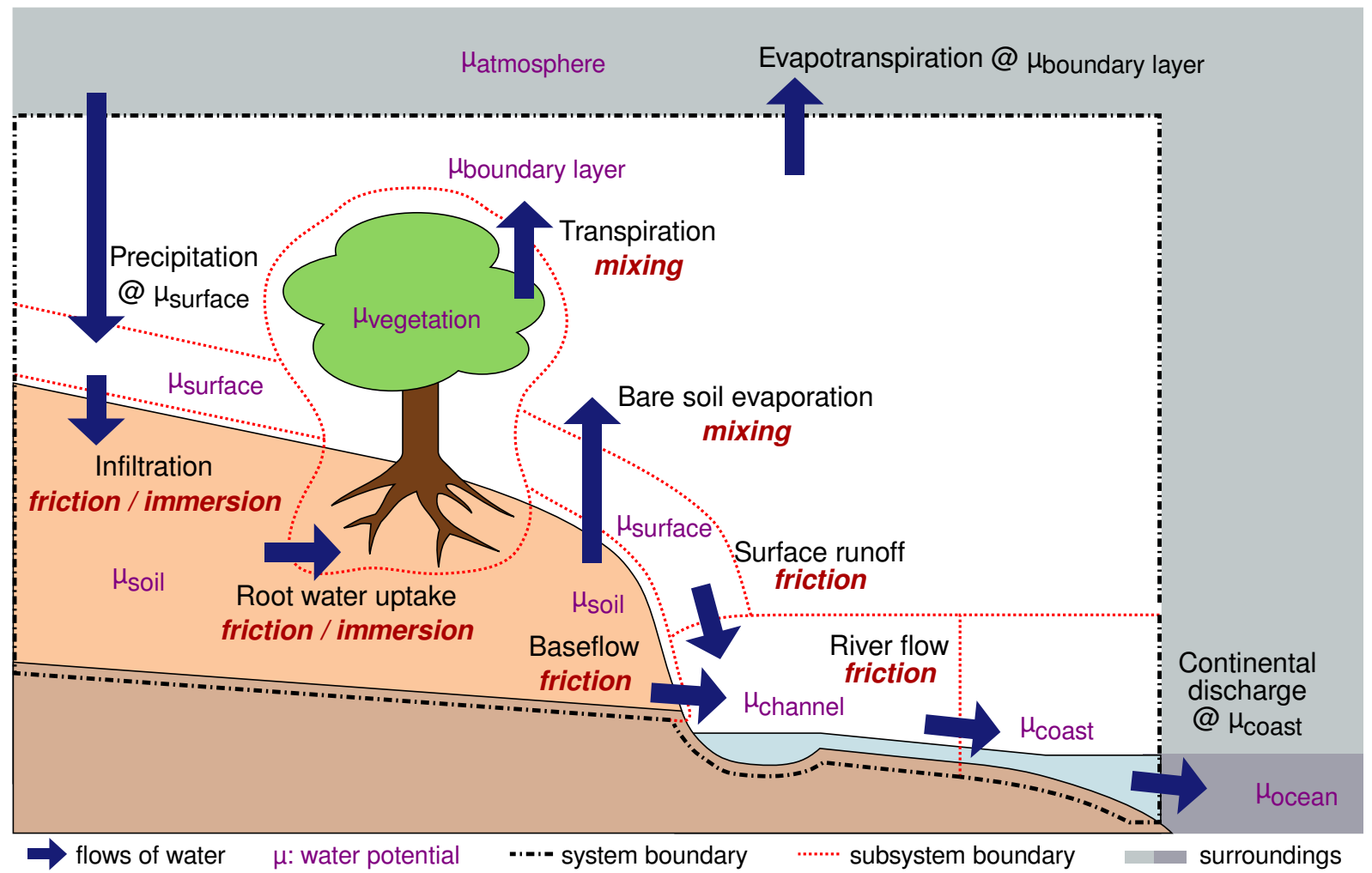

Fig. 1. Overview of the flows of water (black text, regular) and the associated entropy producing dissipative processes (red text, italics) quantified in JESSY and SIMBA. The grey shaded areas correspond to the surroundings of the system.

between the atmosphere and the surface water reservoirs (rivers, lakes) was not considered since the model does not contain an explicit formulation of the river network. Hydraulic redistribution cannot be properly described with the simple bucket model used here and is therefore not included. Water flow from the river channel back to the soil does not seem to play a large role at the scale of a model grid cell and is neglected.

Note that all entropy production terms considered in the model are due to processes within the system "land surface". Since the system is assumed to be in steady state, the entropy produced in the soil or the vegetation is completely exported to the surroundings (Kondepudi and Prigogine, 1998, p. 387). Hence, the external entropy exchange flows are not considered explicitly in our calculation. The assumption of steady state also means that the reservoirs of the hydrological cycle at the land surface such as the soil water storage do not change if averaged over long time periods (several decades).

A list of the most important model variables and parameters can be found in Table A1. All model parameter values are globally uniform, which is reasonable considering the simplicity of the model. More complex parametrisations of parts of the model such as different soil types, for instance, would represent an increase in complexity not matched by the other parts of the model, e.g. the vegetation model. Fur- thermore, the model is not very sensitive to the parameter soil type, probably due to its simplicity.

\subsection{The potential of water in different parts of the hydrological system}

The potential of water vapour in the atmospheric boundary layer is written as (Kleidon and Schymanski, 2008):

$\mu_{\text {boundary layer }}=R_{\text {spec,vap }} T_{\text {air }} \ln (\Phi)+g z$

where $R_{\text {spec,vap }}$ is the specific gas constant of water vapour, $T_{\text {air }}$ is the temperature of the atmospheric boundary layer, $\Phi$ is the relative humidity of the air, $g$ is the gravitational acceleration and $z$ is the height above mean sea level.

Soil water potential $\mu_{\text {soil }}$ is formulated as the sum of the modified matric potential $\Psi_{\mathrm{M}}$ and the gravitational potential of water in the soil (Kleidon and Schymanski, 2008). In general, both potentials vary with the height $z$ of the soil water:

$\mu_{\text {soil }}(z)=\Psi_{\mathrm{M}}(z)+g z$

where $g$ is the gravitational acceleration. The gravitational potential increases linearly with $z$. The value of the matric potential $\Psi_{\mathrm{M}}$ at height $z$ depends on the relative soil water content $\Theta_{\text {soil }}(z)$ at that height. In unsaturated conditions, the relation between $\Psi_{\mathrm{M}}(z)$ and $\Theta_{\text {soil }}(z)$ is determined by the 


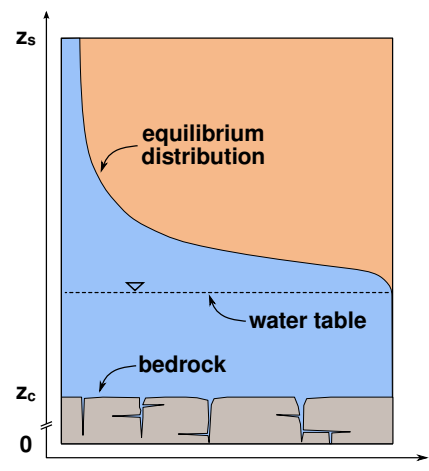

soil moisture

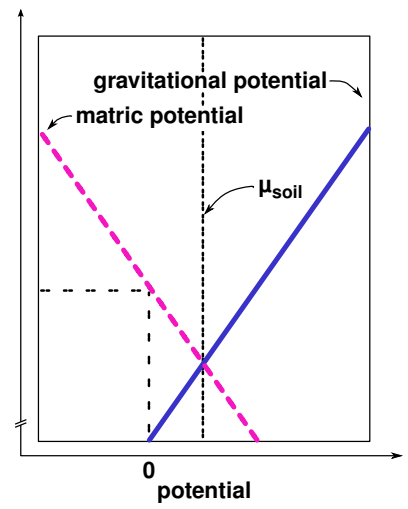

Fig. 2. Left: equilibrium distribution of soil water inside the bucket, $z_{\mathrm{s}}$ and $z_{\mathrm{c}}$ correspond to the height of the surface and the channel, respectively. Right: soil water potential $\mu_{\text {soil }}$ as a function of height.

van-Genuchten soil water retention curve (van Genuchten, 1980; Mualem, 1976). The value of $\Psi_{M}(z)$ is negative and decreases with decreasing saturation degree. This means that the more unsaturated the soil is, the more work has to be performed to extract water from the soil matrix. The matric potential is written as:

$\Psi_{\mathrm{M}}(z)=-\frac{g}{\alpha_{\mathrm{vg}}}\left(\left(\frac{\Theta_{\text {soil }}(z)}{\Theta_{\text {soil } \max }}\right)^{-\frac{1}{m_{\mathrm{vg}}}}-1\right)^{\frac{1}{n_{\mathrm{vg}}}}$

$\Theta_{\text {soil }}$ is defined as $\mathrm{m}^{3}$ extractable water $\mathrm{m}^{-3}$ soil. The relation to saturation $S$ is: $S=\Theta_{\text {soil }} / \Theta_{\text {soil, } \max }=\left(\theta-\theta_{\mathrm{r}}\right) /\left(\theta_{\mathrm{s}}-\theta_{\mathrm{r}}\right)$ where $\Theta_{\text {soil,max }}$ is the relative extractable water content at saturation. $\theta$ is the volumetric relative water content of the soil in $\mathrm{m}^{3}$ water $\mathrm{m}^{-3}$ soil, $\theta_{\mathrm{r}}$ is the residual relative soil water content and $\theta_{\mathrm{S}}$ is the relative water content at saturation as defined in van Genuchten (1980). In the model used in this study $\theta_{\mathrm{r}}$ and $\theta_{\mathrm{s}}$ are set to values corresponding to the soil type sandy loam (Carsel and Parrish, 1988) which can be found in Table A1. $m_{\mathrm{vg}}, n_{\mathrm{vg}}$, and $\alpha_{\mathrm{vg}}$ are the parameters of the van-Genuchten soil water retention curve and their values correspond to the soil type sandy loam, too. Under saturated conditions, $\Psi_{\mathrm{M}}(z)$ is replaced by the hydraulic head (Atkins, 1998).

To obtain the value of $\mu_{\text {soil }}$ for the whole soil column, it is assumed that the water reaches a vertical equilibrium distribution in each time step of the model. Consequently, the soil water potential is constant across the soil profile, $\mu_{\text {soil }}(z)=$ const. This, however, requires a vertically nonuniform distribution of the water in the soil column (see Fig. 2). Each possible value of $\mu_{\text {soil }}(z)=$ const is then associated with a different vertical equilibrium distribution of water. To assign the correct value of $\mu_{\text {soil }}$ to a given relative water content of the soil $\Theta_{\text {soil }}$ the equilibrium soil moisture distribution whose integral is equal to the value of $\Theta_{\text {soil }}$ is calculated. The relationship of $\mu_{\text {soil }}$ and water content $\Theta_{\text {soil }}$ is shown in Fig. 3.
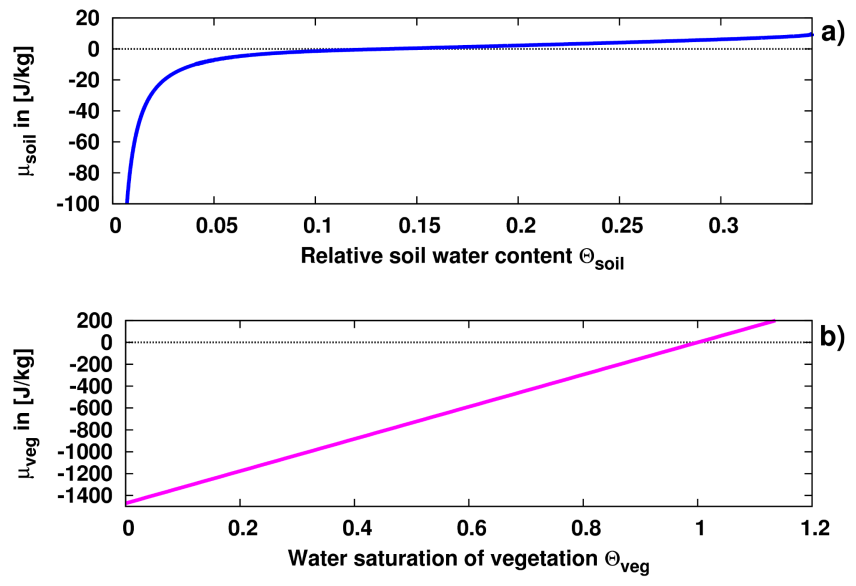

Fig. 3. (a) Soil water potential $\mu_{\text {soil }}$ as a function of relative water content of the soil, $\Theta_{\text {soil }}$ and (b) vegetation water potential $\mu_{\mathrm{veg}}$ as a function of the water saturation of the vegetation, $\Theta_{\mathrm{veg}}$.

The height of the soil surface is denoted by $z_{\mathrm{s}}$. The potential of free water at the soil surface $\mu_{\text {surface }}$ is then set to the gravitational potential at $z_{\mathrm{s}}$ since rain is free water. The potential of free water in the river channel, $\mu_{\text {channel }}$, is set to the gravitational potential at the height $z_{\mathrm{c}}$ of the channel.

The potential of water in the vegetation, $\mu_{\mathrm{veg}}$ is described by:

$\mu_{\mathrm{veg}}=\left(\Theta_{\mathrm{veg}}-1.0\right) \Psi_{\mathrm{PWP}}$

where $\Psi_{\mathrm{PWP}}$ is the permanent wilting point which is set to a value of $1471.5 \mathrm{~J} \mathrm{~kg}^{-1}$. This value results from multiplying the wilting point (150 m, based on Hillel, 1998, p. $144 \mathrm{ff}$ ) with the gravitational acceleration. $\Theta_{\text {veg }}$ is the relative water content of the vegetation (see Fig. 3). $\mu_{\mathrm{veg}}$ decreases linearly with plant available water content (Roderick and Canny, 2005; Schymanski, 2007) to the minimum possible root water potential at the wilting point.

\subsection{Calculation of entropy production by flows of water}

Root water uptake is described in JESSY as a function of the gradient in water potential between the soil and the vegetation according to:

$q_{\text {root }}=c_{\text {root }}\left(\mu_{\text {soil }}-\mu_{\mathrm{veg}}\right)$

where $\mu_{\text {soil }}$ is the soil water potential, $\mu_{\mathrm{veg}}$ is the potential of water in the vegetation and $c_{\text {root }}$ is an effective conductivity at the soil-root interface (see Table A1 and Eqs. 4 and 2). The entropy production of root water uptake is formulated as:

$\sigma_{\text {root }}=q_{\text {root }} \rho \frac{\mu_{\text {soil }}-\mu_{\mathrm{veg}}}{T_{\text {soil }}}$

where $T_{\text {soil }}$ is the soil temperature and $\rho$ is the density of water which is used to express the entropy production in the units $\mathrm{W} \mathrm{m}^{-2} \mathrm{~K}^{-1}$. 
Baseflow is expressed as:

$q_{\text {base }}=c_{\text {base }}\left(\mu_{\text {soil }}-\mu_{\text {channel }}\right)$

where $\mu_{\text {channel }}$ is the potential of water in the river channel and $c_{\text {base }}$ corresponds to the effective conductivity of the interface between the soil and channel. The entropy production of baseflow is calculated as:

$\sigma_{\text {base }}=q_{\text {base }} \rho \frac{\mu_{\text {soil }}-\mu_{\text {channel }}}{T_{\text {soil }}}$

Bare soil evaporation $q_{\text {evap }}$ and transpiration $q_{\text {trans }}$ are calculated by the minimum of atmospheric demand $q_{\text {epot }}$ and the amount of water which is available for evaporation from the soil and the vegetation during a day:

$q_{\text {evap }}=\min \left(q_{\text {epot }}, \frac{\Theta_{\text {soil }} \Delta_{\mathrm{S}}}{\Delta_{\mathrm{t}}}\right)$

$q_{\text {trans }}=\min \left(q_{\text {epot }}, \frac{\Theta_{\mathrm{veg}} \Delta_{\mathrm{V}}}{\Delta_{\mathrm{t}}}+q_{\mathrm{root}}\right)$

$\Delta_{\mathrm{S}}$ and $\Delta_{\mathrm{V}}$ are the "bucket depths" of soil and vegetation, respectively, and $\Delta_{\mathrm{t}}$ is the model time step which is set to a day. The demand $q_{\text {epot }}$ is quantified by an equilibrium evaporation approach (McNaughton and Jarvis, 1983):

$q_{\text {epot }}=\left(\frac{\frac{d s}{d T}}{\frac{d s}{d T}+\gamma} f_{\text {net }, \Gamma}\right) / \lambda$

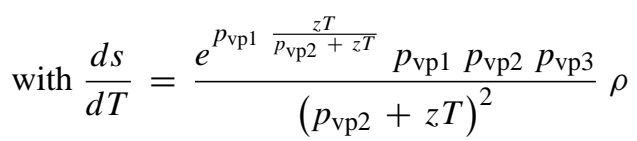

where $z T$ corresponds to (surface temperature in $\mathrm{K}$ - melting temperature of water), $f_{\text {net, } \Gamma}$ is net radiation and $\frac{d s}{d T}$ is the slope of the saturation vapour pressure versus temperature relationship. The values of the parameters $\lambda, p_{\mathrm{vp} 1}, p_{\mathrm{vp} 2}$, $p_{\mathrm{vp} 3}, \rho$ and $\gamma$ can be found in Table A1. To account for the decrease in hydraulic conductivity at lower soil water contents, bare soil evaporation takes place only as long as the difference between the maximum relative soil water content and the actual one is smaller than 0.01. This value is chosen such that, assuming a vertical equilibrium soil water distribution, the decrease in hydraulic conductivity at the top of the soil column is approximately 2 orders of magnitude (van Genuchten, 1980). Since bare soil evaporation is small on vegetated surfaces, it is constrained to the fraction of bare soil in each grid cell. The entropy production of bare soil evaporation and transpiration is written as:

$\sigma_{\text {evap }}=q_{\text {evap }} \rho \frac{\mu_{\text {soil }}-\mu_{\text {boundary layer }}}{T_{\text {surf }}}$
$\sigma_{\text {trans }}=q_{\text {trans }} \rho \frac{\mu_{\text {veg }}-\mu_{\text {boundary layer }}}{T_{\text {surf }}}$

www.earth-syst-dynam.net/2/179/2011/ where $\mu_{\text {boundary layer }}$ is the water vapour potential of the atmospheric boundary layer and $T_{\text {surf }}$ is the surface temperature.

Surface runoff is described as saturation excess flow and is consequently controlled by the bucket size (see Table A1). The entropy production of surface runoff is then calculated as:

$\sigma_{\text {surf }}=q_{\text {surf }} \rho \frac{\mu_{\text {surface }}-\mu_{\text {channel }}}{T_{\text {surf }}}$

where $\mu_{\text {surface }}$ and $\mu_{\text {channel }}$ are used because free water flows from the soil surface into the nearest river channel. The entropy production of the river discharge $q_{\text {river }}$ into the oceans, which consists of water from surface runoff and baseflow, is then written as:

$\sigma_{\text {river }}=\left(q_{\text {surf }}+q_{\text {base }}\right) \rho \frac{\mu_{\text {channel }}-\mu_{\text {msl }}}{T_{\text {surf }}}$

where $\mu_{\mathrm{msl}}$ corresponds to the potential of free water at mean sea level, which is set to zero. Since the gradients $\mu_{\text {surface }}-$ $\mu_{\text {channel }}$ and $\mu_{\text {channel }}-\mu_{\mathrm{msl}}$ are constant, both $\sigma_{\text {surf }}$ and $\sigma_{\text {river }}$ vary only with the flow rate.

Additionally, entropy is produced during the infiltration of water into the soil, which is formulated as:

$\sigma_{\text {inf }}=\left(q_{\text {rain }}-q_{\text {surf }}\right) \rho \frac{\mu_{\text {surface }}-\mu_{\text {soil }}}{T_{\text {soil }}}$

where $q_{\text {rain }}-q_{\text {surf }}$ is the amount of infiltrated water and $\mu_{\text {surface }}-\mu_{\text {soil }}$ is the gradient between free water at the surface and bound water in the soil.

\section{Model setup}

JESSY and SIMBA are run on a global rectangular T42 grid (2.8125 degree resolution) with a climate data set (1971 to 2006; Sheffield et al., 2006) that consists of shortwave radiation, downwelling longwave radiation, precipitation, average temperature and minimum temperature at $2 \mathrm{~m}$ height on a daily basis. Terrestrial longwave radiation and relative humidity are derived from these variables (see Porada et al., 2010 for further information). The model is run until all variables are in a dynamic steady state. The model output is then obtained by averaging over the last $10 \mathrm{yr}$ of the simulation.

\subsection{Observational datasets to test the model}

JESSY and SIMBA are evaluated by comparing the model output to datasets containing runoff, evapotranspiration, Net Primary Productivity (NPP) and soil carbon. This method has already been used to evaluate the basic version of the model (Porada et al., 2010).

In a first test, runoff output from JESSY is compared to river basin discharge data from the 35 largest catchments by area of the world. A basin mask from Vörösmarty et al. (2000) is used to identify the model grid cells contributing 
to a certain basin. The discharge data is taken from Dai and Trenberth (2002). An overview of the basins can be found in Fig. A1.

In a second test, modelled evapotranspiration for each grid cell is compared with the one predicted by the empirical Budyko curve (Budyko, 1974). The Budyko-curve estimates evapotranspiration as a function of a climate index, which is calculated from net radiation and precipitation. These are taken from the climate input dataset. The climate index is then calculated for each of the 35 largest river basins as a function of the mean net radiation and precipitation over the basin.

In a third test, the NPP and soil carbon content predicted by SIMBA is compared against global datasets. NPP-data is provided by Cramer et al. (1999) and includes the mean of the NPP-estimates of 17 different vegetation models. In this way, the coupled JESSY/SIMBA model can be compared to other recent global vegetation models. Soil carbon estimates for the first meter of the soil column are taken from IGBPDIS (1998). The comparison is performed using latitudinal profiles of NPP and soil carbon.

\subsection{Determining the MEP-state of root water uptake and baseflow}

JESSY and SIMBA contain several unknown parameters, which had to be tuned previously (Porada et al., 2010). In this study, two influential parameters, $c_{\text {root }}$ and $c_{\text {base }}$ (see Eqs. 6 and 8 and Table A1) are instead determined by MEP. This means they are set to values which lead to a maximisation of the entropy production of the flows they control, namely root water uptake and baseflow. Since all model parameters are global, we maximise the global entropy production of one flow, meaning the sum of all model grid cells, to determine the associated parameter.

Maximising the entropy production of both root water uptake and baseflow requires an iterative approach, since the value of one parameter, e.g. $c_{\text {base }}$, may affect the MEP-state with respect to the other parameter, e.g. $c_{\text {root }}$, since $c_{\text {base }}$ determines a boundary condition for root water uptake. Hence, a stepwise approach is chosen to find the MEP-states of root water uptake and baseflow: first, $c_{\text {base }}$ is set to a fixed value and the MEP-state of root water uptake is determined by varying $c_{\text {root }}$ over several orders of magnitude (see Fig. 4). Then, $c_{\text {base }}$ is set to another value and another MEP-state of root water uptake is determined. Thus, an MEP-value of $c_{\text {root }}$ is assigned to each value of $c_{\text {base }}$. Finally, the pair of $c_{\text {base }}$ and $c_{\text {root }}$ which corresponds to an MEP-state of baseflow is selected (see Fig. 4). This is then used for parametrising the model and evaluating it by comparison with the observational data mentioned in Sect. 3.1.
Table 1. Global land surface mean values of entropy production averaged over $10 \mathrm{yr}$ of simulation with the JESSY/SIMBA model which is parametrised according to MEP.

\begin{tabular}{lcr}
\hline Hydrological process & $\begin{array}{r}\text { Entropy production } \\
\text { in } \mathrm{mW} \mathrm{m} \mathrm{K}^{-2} \mathrm{~K}^{-1}\end{array}$ & $\begin{array}{r}\text { Flow of water } \\
\text { in } \mathrm{km}^{3} \mathrm{yr}^{-1}\end{array}$ \\
\hline Transpiration & 2.4 & 74682 \\
River discharge & $1.1 \mathrm{E}-1$ & 27786 \\
Root water uptake & $7.9 \mathrm{E}-2$ & 74624 \\
Infiltration & $5.1 \mathrm{E}-2$ & 91415 \\
Evaporation & $4.5 \mathrm{E}-4$ & 21 \\
Baseflow & $6.8 \mathrm{E}-5$ & 16814 \\
Surface runoff & $9.1 \mathrm{E}-8$ & 10972 \\
\hline
\end{tabular}

\section{Results}

By varying the two unknown model parameters $c_{\text {root }}$ and $c_{\text {base }}$, the values corresponding to maximum entropy production of the flows root water uptake and baseflow are determined (see Sect. 3.2). These are $c_{\text {root }}=3.5 \mathrm{E}-11 \mathrm{~s} \mathrm{~m}^{-1}$ and $c_{\text {base }}=8.6 \mathrm{E}-9 \mathrm{~s} \mathrm{~m}^{-1}$ (see Fig. 4). The model output obtained by this parametrisation is then evaluated.

\subsection{Model evaluation}

To evaluate JESSY and SIMBA, the model output is compared to observational data described in Sect. 3.1. All variables contained in the datasets are affected by the parameters $c_{\text {root }}$ and $c_{\text {base }}$ that are optimised according to MEP. While runoff and evapotranspiration are directly controlled by root water uptake and baseflow, NPP and soil carbon are influenced through the effect of root water uptake on the productivity of vegetation. The results of the evaluation are shown in Fig. 5.

The model output shows reasonable agreement with observational data. Both general patterns and absolute values of runoff, evapotranspiration, NPP and soil carbon predicted by the model are close to observations. Considering the Budyko-curve, modelled runoff in the northern temperate regions seems to be slightly too high. In comparison with runoff data, however, the model seems to slightly underestimate runoff in these regions. A possible reason to explain both mismatches is underestimation of precipitation in the model input data of the northern regions, as discussed in Porada et al. (2010).

\subsection{Entropy budget of soil hydrological processes}

The results of the entropy budget of the hydrological cycle (Eqs. 6 to 16) are shown in Fig. 6 and in Table 1. Note the different scale ranges below each plot.

It can be seen that the entropy production due to transpiration dominates over other processes. The reason for this 

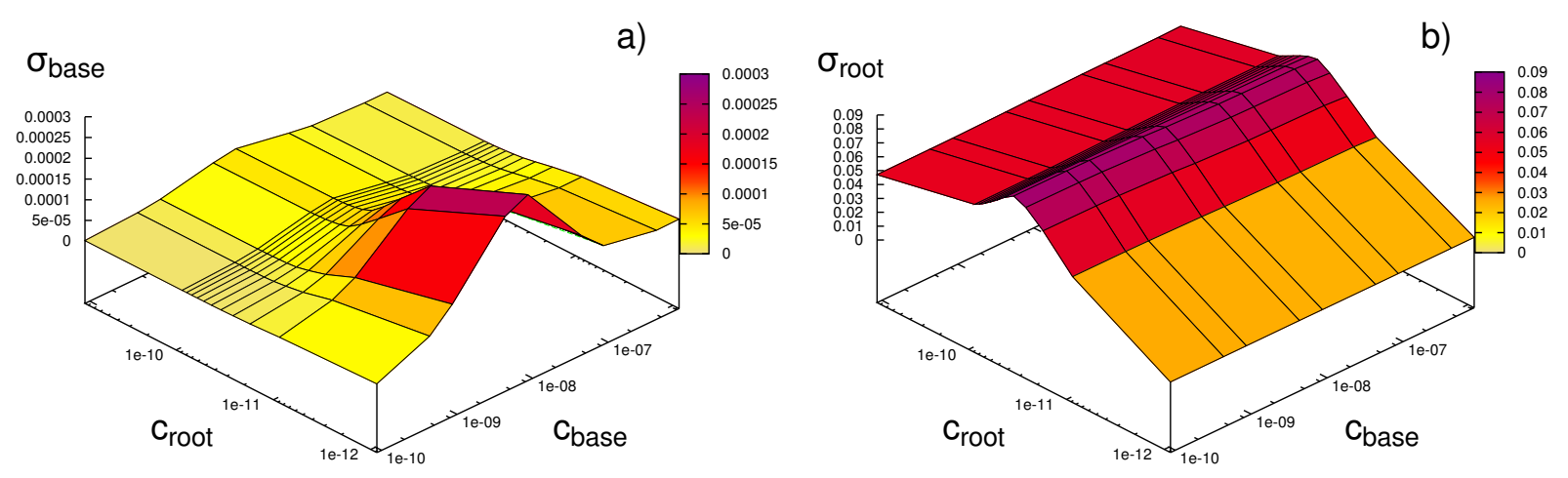

Fig. 4. Entropy production of (a) baseflow and (b) root water uptake as a function of the two model parameters $c_{\text {base }}$ and $c_{\text {root. The combined }}$ MEP-state of baseflow and root water uptake lies at the intersection of the two "ridges" in (a) and (b), the corresponding values can be found in Table A1.

is the large share of transpiration on the global water balance combined with a strong gradient between vegetation and atmosphere. The latter also leads to a relatively high entropy production of bare soil evaporation compared to the small contribution of evaporation to the water balance ( 3 orders of magnitude smaller than other flows). The gradients associated with root water uptake and infiltration are much smaller, thereby leading to smaller values of the corresponding entropy production. While baseflow and surface runoff contribute little to the entropy budget due to the very small gradients in water potential associated with these processes, river discharge results in a relatively high entropy production, especially in mountainous regions characterised by high potential energy of water and high runoff.

\section{Discussion}

Non-equilibrium thermodynamics provides an additional constraint for the formulation of soil hydrological processes, which is usually not considered explicitly. Flows of water are not only constrained by the mass balance, but they are also driven by gradients in water potential between two locations. The formulation of flows and gradients then directly leads to the quantification of the entropy production of hydrological processes. The entropy production characterises the irreversibility of these processes. This is illustrated in Table 1: although root water uptake is of the same order of magnitude as baseflow, it is much more irreversible due to the strong gradient in water potential between soil and atmosphere.

Apart from extending the theoretical basis of a hydrological model, the thermodynamic approach also makes possible the testing of the Principle of Maximum Entropy Production (MEP). By applying MEP to the JESSY/SIMBA model, the values of two unknown model parameters that otherwise would have to be tuned can be determined. In spite of the simplicity of the model, the output of the MEP-parametrised
JESSY/SIMBA agrees well with observational data. This suggests that MEP can be used in this case to determine unknown parameter values instead of tuning them. In the scope of behavioral modeling (Schaefli et al., 2011), this means that MEP can be used as an organising principle in soil hydrology at the global scale. The identification of organising principles such as MEP potentially plays a large role for improving hydrological models, since these principles are assumed to be generally valid and independent of changes in the forcing or in the structure of the system. Using a model as a tool to identify the underlying organising principles thus represents a new approach to modelling hydrological processes and an alternative to parameter tuning.

The reason why deriving model parameter values by MEP leads to realistic predictions is still a matter of discussion. One possible explanation could be that MEP is a physical principle and systems "vary" their properties (expressed by parameters such as $c_{\text {root }}$ and $c_{\text {base }}$ ) to achieve maximum entropy production. Alternatively, MEP can be interpreted as an algorithm to objectively "guess" some outcomes of a model given the information contained in that model. Hence unknown parameters such as $c_{\text {root }}$ and $c_{\text {base }}$ can be derived since the remaining model structure is sufficient to correctly represent all important processes (Dewar, 2009).

Although some of the soil hydrological processes in the JESSY/SIMBA model can be parametrised by MEP, other parts of the model still need to be reformulated using a thermodynamic approach. Soil water, for instance, is assumed to reach a vertical equilibrium distribution in each time step of the model. This may not be possible in case vertical gradients in soil water potential are insufficient to drive a strong water movement towards equilibrium. Since a bucket model is not able to represent vertical gradients in water potential, a layered model is needed here. Varying the conductivities between the layers, the flow of water through the soil could then be determined by MEP. Furthermore, evapotranspiration should be written as a function of the gradient in relative humidity instead of using the minimum of supply and demand 

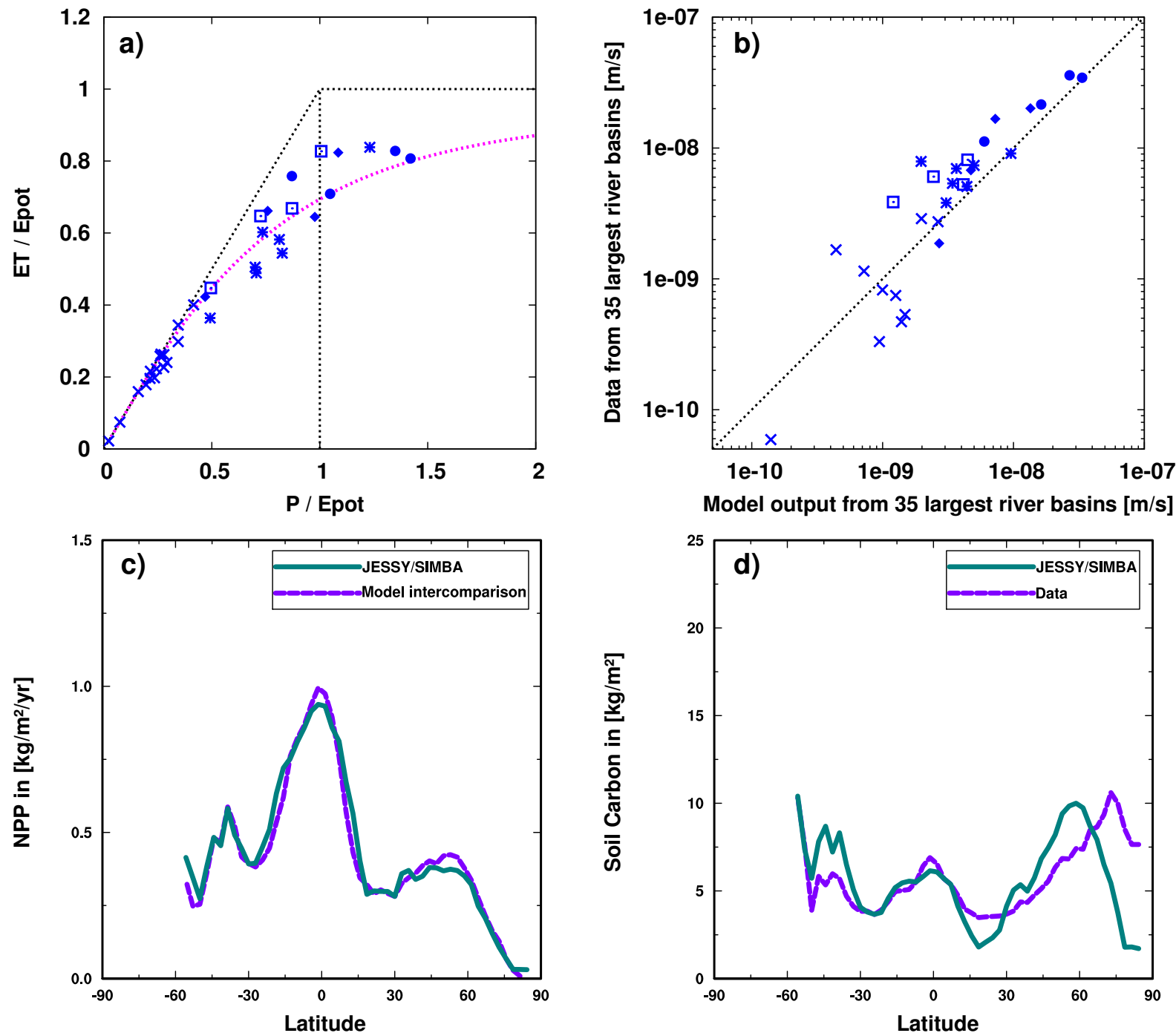

Fig. 5. (a) Modelled evapotranspiration averaged over a basin plotted against the theoretical Budyko-curve (magenta, dashed) for the 35 world's largest river basins. (b) Scatterplot of modelled runoff and measured runoff for the 35 largest river basins of the world. • corresponds to humid tropical, $\diamond$ humid subtropical, $\square$ temperate, $*$ cold continental and $\times($ semi) arid climate regions. (c) Latitudinal pattern of modelled NPP (blue, solid) and the mean NPP of 17 global vegetation models (magenta, dashed) latitudinal pattern of modelled (blue, solid) and measured soil carbon (magenta, dashed), both accumulated over the first meter of the soil. All shown model estimates are derived from a MEP-based parametrisation. They are average values over the last $10 \mathrm{yr}$ of a simulation.

(see Eq. 11). In the current implementation, this gradient is represented only indirectly by the saturation vapour pressure versus temperature relationship $\frac{d s}{d T}$. Not only flows of water, but also carbon fluxes could be described in thermodynamic terms. MEP could be useful here since the parametrisation of diverse vegetation is difficult and often arbitrary. Moreover, additional entropy producing hydrological processes at the land surface could be included in the model. Among these are heat diffusion associated with temperature changes of soil water, irreversible chemical reactions of water with other substances within the soil and physical transformations of the soil, including frost heaving and soil erosion.
Errors concerning the quantification of the entropy production in the model can result from the underestimation of spatial and temporal variability due to the resolution of the model. This means that spatial gradients in water potential or temporal variability of rainfall, for instance, are not captured by the mean values used for a grid cell. Since these gradients could contribute to further entropy production, averaging might lead to underestimation of the entropy produced. Another drawback of the relatively coarse resolution of the model is the fact, that small-scale hydrological processes such as interflow are not considered. It should be pointed out here that the relative importance of the different hydrological processes and their associated entropy 

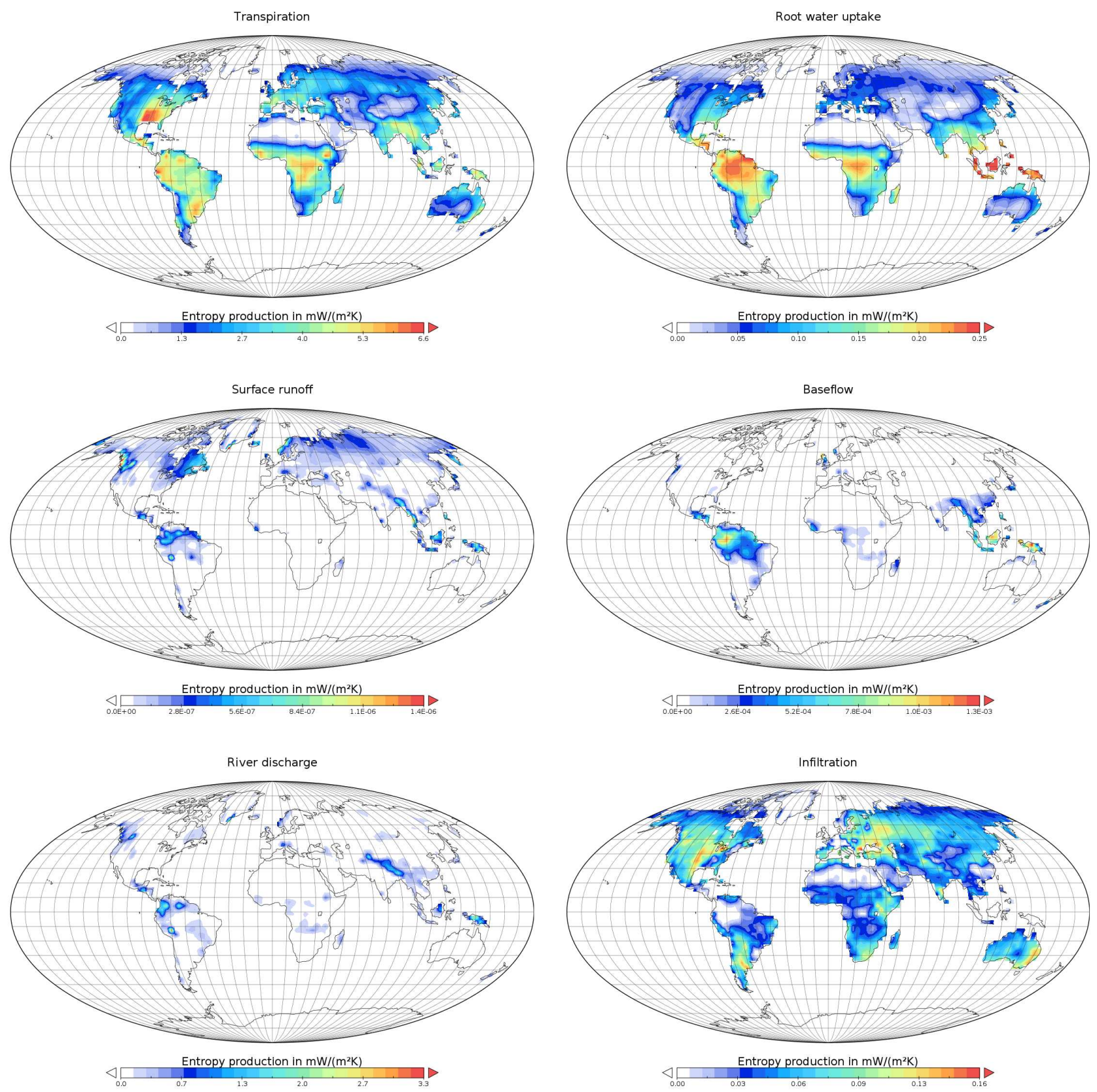

Fig. 6. The global distribution of the entropy production of the most important soil hydrological processes is shown, quantified by the MEPbased JESSY/SIMBA model: Transpiration, root water uptake, surface runoff, baseflow, river discharge and infiltration. All model estimates are average values over the last $10 \mathrm{yr}$ of a simulation.

production could change on smaller scales. Hence, the conclusions of this study are restricted to large-scale hydrological processes. Further errors could arise from the time step of the model: since the potential depends on the water content the gradient is usually reduced by the flow of water during a time step. Hence, the equations that include $\mu_{\text {soil }}, \mu_{\text {veg }}$ and

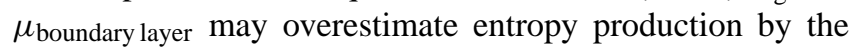
respective processes since the value of the potential is kept constant during a time step. This artificially maintains a high gradient which results in higher entropy production. Consequently, the time step should not be too long. It is difficult, however, to estimate the magnitude of the errors mentioned above since no numbers of global entropy production due to hydrological processes exist to our knowledge. A rough estimate has been made by Kleidon et al. (2009) and their numbers of the entropy production of evapotranspiration and 
river discharge are of the same order of magnitude as the ones calculated by JESSY/SIMBA.

Hence, considering the limitations of the model presented here and the possibilities for future applications, this study can be seen as a first step towards a description of earth system processes which is based on general principles and which is not heavily relying on calibrated parameters.

\section{Conclusions}

In this study a simple model of water and carbon fluxes at the land surface, JESSY/SIMBA, which contains a thermodynamic formulation of soil hydrological processes, is used. This framework describes flows of water as functions of gradients in the combined chemical and gravitational potential of water. It allows for the quantification of an entropy budget of the hydrological cycle at the land surface and also for the testing of the principle of Maximum Entropy Production (MEP). This principle can be used to determine unknown model parameters. Hence, the model is parametrised according to MEP and is then evaluated by comparing the model output with observational data. The results of the evaluation are reasonable which shows that MEP can be successfully applied to the model. Consequently, the approach presented here could be used as a basis for further applications of thermodynamics to land surface and vegetation models, leading to increased physical consistency and reliability of these models. This is crucial for understanding and predicting interactions and feedbacks at the land surface resulting from global change.

\section{Appendix A}

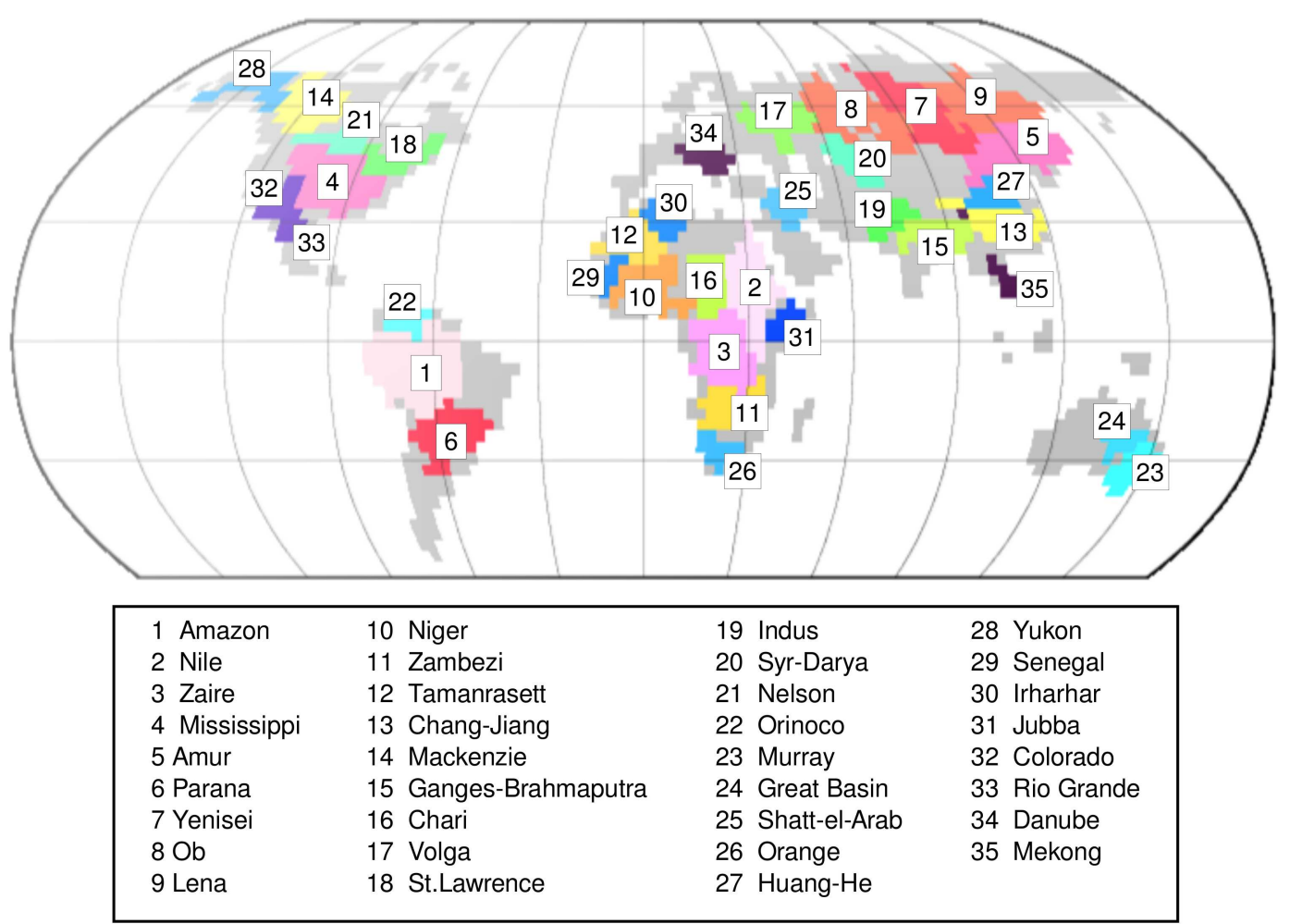

Fig. A1. Overview of the 35 largest catchments by area of the world. 
Table A1. Description of model variables and parameters.

\begin{tabular}{|c|c|c|c|c|}
\hline & Symbol & Description & Value & Units \\
\hline \multirow[t]{3}{*}{ pools } & $\Theta_{\text {veg }}$ & relative vegetation water content & & \\
\hline & $\Theta_{\text {soil }}$ & relative soil water content & & \\
\hline & $\mathrm{C}_{\text {soil }}$ & organic carbon in soil & & $\mathrm{kgC} \mathrm{m}^{-2}$ \\
\hline \multirow[t]{8}{*}{ states } & $T_{\text {soil }}$ & soil temperature & & $\mathrm{K}$ \\
\hline & $T_{\text {surf }}$ & surface temperature & & $\mathrm{K}$ \\
\hline & $T_{\text {air }}$ & air temperature & & $\mathrm{K}$ \\
\hline & $\mu_{\text {boundary layer }}$ & water vapour potential of atmospheric boundary layer & & $\mathrm{J} \mathrm{kg}^{-} 1$ \\
\hline & $\mu_{\mathrm{veg}}$ & vegetation water potential & & $\mathrm{J} \mathrm{kg}^{-} 1$ \\
\hline & $\mu_{\text {soil }}$ & soil water potential & & $\mathrm{J} \mathrm{kg}^{-} 1$ \\
\hline & $\mu_{\text {channel }}$ & potential of water in a river channel & & $\mathrm{J} \mathrm{kg}^{-} 1$ \\
\hline & $\begin{array}{l}\mu_{\text {surface }} \\
\Phi\end{array}$ & $\begin{array}{l}\text { potential of rain at surface } \\
\text { relative humidity }\end{array}$ & & $\mathrm{J} \mathrm{kg}^{-} 1$ \\
\hline \multirow[t]{15}{*}{ rates } & $q_{\text {rain }}$ & rainfall & & $\mathrm{ms}^{-1}$ \\
\hline & $q_{\text {root }}$ & root water uptake & & $\mathrm{m} \mathrm{s}^{-1}$ \\
\hline & $q_{\text {base }}$ & baseflow & & $\mathrm{m} \mathrm{s}^{-1}$ \\
\hline & $q_{\text {trans }}$ & transpiration & & $\mathrm{m} \mathrm{s}^{-1}$ \\
\hline & $q_{\text {evap }}$ & evaporation & & $\mathrm{m} \mathrm{s}^{-1}$ \\
\hline & $q_{\text {surf }}$ & surface runoff & & $\mathrm{m} \mathrm{s}^{-1}$ \\
\hline & $q_{\text {river }}$ & river discharge & & $\mathrm{m} \mathrm{s}^{-1}$ \\
\hline & NPP & Net Primary Productivity & & $\mathrm{kgC} \mathrm{m}^{-2} \mathrm{yr}^{-1}$ \\
\hline & $\sigma_{\text {evap }}$ & entropy production of evaporation & & $\mathrm{W} \mathrm{m}^{-2} \mathrm{~K}^{-1}$ \\
\hline & $\sigma_{\text {trans }}$ & entropy production of transpiration & & $\mathrm{W} \mathrm{m} \mathrm{m}^{-2} \mathrm{~K}^{-1}$ \\
\hline & $\sigma_{\text {root }}$ & entropy production of root water uptake & & $\mathrm{W} \mathrm{m} \mathrm{m}^{-2} \mathrm{~K}^{-1}$ \\
\hline & $\sigma_{\text {base }}$ & entropy production of baseflow & & $\mathrm{W} \mathrm{m} \mathrm{m}^{-2} \mathrm{~K}^{-1}$ \\
\hline & $\sigma_{\text {surf }}$ & entropy production of surface runoff & & $\mathrm{W} \mathrm{m} \mathrm{m}^{-2} \mathrm{~K}^{-1}$ \\
\hline & $\sigma_{\text {river }}$ & entropy production of river discharge & & $\mathrm{W} \mathrm{m}^{-2} \mathrm{~K}^{-1}$ \\
\hline & $\sigma_{\text {inf }}$ & entropy production of infiltration & & $\mathrm{W} \mathrm{m}{ }^{-2} \mathrm{~K}^{-1}$ \\
\hline \multirow[t]{22}{*}{ parameters } & $g$ & gravitational acceleration & 9.81 & $\mathrm{~ms}^{-2}$ \\
\hline & $R_{\mathrm{V}}$ & gas constant of water vapour & 461.5 & $\mathrm{~J} \mathrm{~kg}^{-1} \mathrm{~K}^{-1}$ \\
\hline & $\lambda$ & latent heat of vaporization & $2.45 \mathrm{E} 6$ & $\mathrm{~J} \mathrm{~kg}^{-1}$ \\
\hline & $\gamma$ & psychometric constant & 65.0 & $\mathrm{PaK}^{-1}$ \\
\hline & $p_{\mathrm{vp} 1}$ & parameter to calculate vapour pressure & 17.269 & \\
\hline & $p_{\mathrm{vp} 2}$ & parameter to calculate vapour pressure & 237.3 & $\mathrm{~K}$ \\
\hline & $p_{\mathrm{vp} 3}$ & parameter to calculate vapour pressure & 610.8 & $\mathrm{~Pa}$ \\
\hline & $\rho$ & density of water & 1000.0 & $\mathrm{~kg} \mathrm{~m}^{-3}$ \\
\hline & $z$ & height above mean sea level & & $\mathrm{m}$ \\
\hline & $z_{\mathrm{s}}$ & height of the soil surface above sea level & & $\mathrm{m}$ \\
\hline & $z_{\mathrm{c}}$ & height of the channel above sea level & $z_{\mathrm{s}}-1.0$ & $\mathrm{~m}$ \\
\hline & $\Delta_{\mathrm{S}}$ & depth of the soil bucket & $z_{\mathrm{s}}-z_{\mathrm{c}}$ & $\mathrm{m}$ \\
\hline & $\Delta \mathrm{V}$ & depth of the vegetation bucket & 1.0 & $\mathrm{~m}$ \\
\hline & $c_{\text {root }}$ & effective conductivity at soil-root interface & $3.5 \mathrm{E}-11$ & $\mathrm{~s} \mathrm{~m}^{-1}$ \\
\hline & $c_{\text {base }}$ & effective conductivity at soil-channel interface & $8.6 \mathrm{E}-9$ & $\mathrm{~s} \mathrm{~m}^{-1}$ \\
\hline & $\theta_{\mathrm{r}}$ & residual relative soil water content & 0.065 (sandy loam) & \\
\hline & $\theta_{\mathrm{s}}$ & relative soil water content at saturation & 0.41 (sandy loam) & \\
\hline & $\alpha_{\mathrm{vg}}$ & van Genuchten parameter $\alpha$ & 7.5 (sandy loam) & \\
\hline & $n_{\mathrm{vg}}$ & van Genuchten parameter $n$ & 1.89 (sandy loam) & \\
\hline & $m_{\mathrm{vg}}$ & van Genuchten parameter $m$ & 0.47 (sandy loam) & \\
\hline & $\Theta_{\text {soil,max }}$ & relative extractable soil water content at saturation & 0.345 & \\
\hline & $\Psi_{\mathrm{PWP}}$ & permanent wilting point & 1471.5 & $\mathrm{~J} \mathrm{~kg}^{-} 1$ \\
\hline
\end{tabular}


Acknowledgements. The authors are thankful to Fabian Gans for useful discussions about the topic. We thank the Helmholtz Alliance "Planetary Evolution and Life" for funding and two anonymous reviewers for helpful comments.

\section{Edited by: R. Niven}

The service charges for this open access publication have been covered by the Max Planck Society.

\section{References}

Atkins, P. W.: Physical Chemistry, 6th Edn., Oxford University Press, Oxford, 1998.

Budyko, M.: Climate and life, Academic Press, New York, 1974.

Carsel, R. F. and Parrish, R. S.: Developing Joint Probability Distributions of Soil Water Retention Characteristics, Water Resour. Res., 24, 755-769, doi:10.1029/WR024i005p00755, 1988.

Cramer, W., Kicklighter, D. W., Bondeau, A., Moore III, B., Churkina, G., Nemry, B., Ruimy, A., and Schloss, A.: Comparing global models of terrestrial Net Primary Productivity (NPP): overview and key results, Global Change Biol., 5, 115, doi:10.1046/j.1365-2486.1999.00009.x, 1999.

Dai, A. and Trenberth, K. E.: Estimates of Freshwater Discharge from Continents: Latitudinal and Seasonal Variations, J. Hydrometeorol., 3, 660-687, doi:10.1175/15257541(2002)003<0660:EOFDFC>2.0.CO;2, 2002.

Dewar, R. C.: Maximum Entropy Production as an Inference Algorithm that Translates Physical Assumptions into Macroscopic Predictions: Dont Shoot the Messenger, Entropy, 11, 931-944, doi:10.3390/e11040931, 2009.

Edlefsen, N. E. and Anderson, A. B. C.: Thermodynamics of Soil Moisture, Hilgardia, 15, 31-298, 1943.

Hillel, D.: Environmental Soil Physics, Academic Press, 1998.

IGBP-DIS: SoilData(V.0), A program for creating global soilproperty databases, IGBP Global Soils Data Task, France, 1998.

Kleidon, A. and Schymanski, S.: Thermodynamics and optimality of the water budget on land: A review, Geophys. Res. Lett., 35, L20404, doi:10.1029/2008GL035393, 2008.

Kleidon, A., Schymanski, S. J., and Stieglitz, M.: Thermodynamics, Irreversibility, and Optimality in Land Surface Hydrology, in: Bioclimatology and Natural Hazards, edited by: Střelcová, K., Mátyás, C., Kleidon, A., Lapin, M., Matejka, F., Blaženec, M., S̆kvarenina, J., and Holécy, J., Springer, Berlin, Germany, 107-118, doi:10.1007/978-1-4020-8876-6_9, 2009.

Kondepudi, D. and Prigogine, I.: Modern thermodynamics - from heat engines to dissipative structures, Wiley, Chichester, 1998.

Leopold, L. B. and Langbein, W. L.: The concept of entropy in landscape evolution, US Geol. Surv. Prof. Pap., 500-A, 20, 1962.

Martyushev, L. M. and Seleznev, V. D.: Maximum entropy production principle in physics, chemistry and biology, Phys. Rep., 426, 1-45, doi:10.1016/j.physrep.2005.12.001, 2006.

McNaughton, K. G. and Jarvis, P. G.: Predicting effects of vegetation changes on transpiration and evaporation, in: Water Deficits and Plant Growth, edited by: Kozlowski, T. L., Academic Press, New York, 7, 1-47, 1983.
Mualem, Y.: A new model for predicting the hydraulic conductivity of unsaturated porous media, Water Resour. Res., 12, 513-522, doi:10.1029/WR012i003p00513, 1976.

Ozawa, H., Ohmura, A., Lorenz, R. D., and Pujol, T.: The second law of thermodynamics and the global climate system - a review of the maximum entropy production principle, Rev. Geophys., 41, 1018, doi:10.1029/WR012i003p00513, 2003.

Porada, P., Arens, S., Buendía, C., Gans, F., Schymanski, S. J., and Kleidon, A.: A simple global land surface model for biogeochemical studies, Technical Reports, Max-Planck-Institut für Biogeochemie, Jena, Germany, 18, 2010.

Roderick, M. L. and Canny, M. J.: A mechanical interpretation of pressure chamber measurements - what does the strength of the squeeze tell us?, Plant Physiol. Biochem., 43, 323-336, doi:10.1016/j.plaphy.2005.02.014, 2005.

Schaefli, B., Harman, C. J., Sivapalan, M., and Schymanski, S. J.: HESS Opinions: Hydrologic predictions in a changing environment: behavioral modeling, Hydrol. Earth Syst. Sci., 15, 635646, doi:10.5194/hess-15-635-2011, 2011.

Schymanski, S. J.: Transpiration as the Leak in the Carbon Factory: A Model of Self-Optimising Vegetation, Ph.D. thesis, The University of Western Australia, Perth, Australia, 2007.

Schymanski, S. J., Kleidon, A., and Roderick, M. L.: Ecohydrological Optimality, in: Encyclopedia of Hydrological Sciences, edited by: Anderson, M. G. and McDonnell, J. J., John Wiley \& Sons, Ltd, New York, USA, doi:10.1002/0470848944.hsa319, 2009.

Schymanski, S. J., Kleidon, A., Stieglitz, M., and Narula, J.: Maximum Entropy Production allows simple representation of heterogeneity in arid ecosystems, Philos. T. Roy. Soc. B, 365, 1449 1455, doi:10.1098/rstb.2009.0309, 2010.

Sheffield, J., Goteti, G., and Wood, E. F.: Development of a 50 -yr high-resolution global dataset of meteorological forcings for land surface modeling, J. Climate, 19, 3088-3111, doi:10.1175/JCLI3790.1, 2006.

Sivapalan, M.: Pattern, Process and Function: Elements of a Unified Theory of Hydrology at the Catchment Scale, in: Encyclopedia of Hydrological Sciences, edited by: Anderson, M. G., John Wiley \& Sons, Ltd, New York, USA, 193-219, doi:10.1002/0470848944.hsa012, 2005.

van Genuchten, M. T.: A closed-form equation for predicting the hydraulic conductivity of unsaturated soils, Soil Sci. Soc. Am. J., 44, 892-898, 1980.

Vörösmarty, C., Fekete, B., Meybeck, M., and Lammers, R.: Geomorphometric attributes of the global system of rivers at 30-minute spatial resolution, J. Hydrol., 237, 17-39, doi:10.1016/S0022-1694(00)00282-1, 2000.

Zehe, E., Blume, T., and Blöschl, G.: The principle of maximum energy dissipation: a novel thermodynamic perspective on rapid water flow in connected soil structures, Philos. T. Roy. Soc. B, 365, 1377-1386, doi:10.1098/rstb.2009.0308, 2010. 